\title{
Research on the Correlation Between Activating Transcription Factor 3 Expression in the Human Coronary Artery and Atherosclerotic Plaque Stability
}

\section{J. Peng}

Department of Forensic Medicine, Guizhou Medical University

C. Y. Le

Department of Forensic Medicine, Guizhou Medical University

B. Xia

Department of Forensic Medicine, Guizhou Medical University

J.W. Wang

Department of Forensic Medicine, Guizhou Medical University

J. J. Liu

Department of Forensic Medicine, Guizhou Medical University

Z. Li

Department of Forensic Medicine, Guizhou Medical University

Q.J.Zhang

Department of Forensic Medicine, Guizhou Medical University

Q. Zhang

Department of Forensic Medicine, Guizhou Medical University

\section{J. Wang}

Department of Forensic Medicine, Guizhou Medical University

C.W.Wan (D wcw005@sina.com)

Department of Forensic Medicine, Guizhou Medical University

\section{Research Article}

Keywords: Atherosclerosis, ATF3, plaque stability, inflammatory reaction, coronary heart disease

Posted Date: February 3rd, 2021

DOI: https://doi.org/10.21203/rs.3.rs-155718/v1

License: (1) (1) This work is licensed under a Creative Commons Attribution 4.0 International License.

Read Full License 
Version of Record: A version of this preprint was published at BMC Cardiovascular Disorders on July 28th, 2021. See the published version at https://doi.org/10.1186/s12872-021-02161-9. 


\title{
${ }^{1}$ Research on the correlation between activating transcription factor 3 expression in the human coronary artery and atherosclerotic plaque stability
}

\author{
J. Peng ${ }^{1}$, C.Y. Le ${ }^{1}$, B. Xia ${ }^{1}$, J.W. Wang ${ }^{1}$, J.J. Liu ${ }^{1}$, Z. Li ${ }^{1}$, Q.J. Zhang ${ }^{1}$, Q. Zhang ${ }^{1}$, J.
} Wang $^{1, *}$, C.W. Wan ${ }^{1, *}$

\begin{abstract}
Background: Activating transcription factor 3 (ATF3) is an early response gene that is activated in response to atherosclerotic stimulation and may be an important factor in inhibiting the progression of atherosclerosis. In this study, we directly measured the expression of ATF3 and inflammatory factors in human coronary atherosclerotic plaques to examine the relationship between ATF3 expression, inflammation and structural stability in human coronary atherosclerotic plaques.
\end{abstract}

Methods: A total of 68 coronary artery specimens were collected from the autopsy group, including 36 cases of sudden death from coronary heart disease (SCD group) and 32 cases of acute death caused by mechanical injury with coronary atherosclerosis (CHD group). Twenty-two patients who had no coronary heart disease were collected as the control group (CON group). Haematoxylin-eosin staining was used to observe changes in arterial structure. Western blotting and immunohistochemistry were used to measure the expression and distribution of ATF3,

\footnotetext{
* Correspondence:wcw005@sina.com; wj6400@gmc.edu.cn

1 Department of Forensic Medicine, Guizhou Medical University, Guizhou, Guiyang 550000, China

Full list of author information is available at the end of the article
} 
inflammatory factors and matrix metalloproteinase-9 (MMP-9) and vascular cell adhesion molecule 1 (VCAM1) in the coronary artery. The Pearson correlation coefficient was used to analyse the correlation between ATF3 protein expression and inflammatory factors and between ATF3 protein expression and structure-related indexes in the lesion group.

Results: Compared with those in the control group, the intima and necrotic core in the coronary artery were thickened, the fibrous cap became thin and the degree of vascular stenosis was increased in the lesion group, while the intima and necrotic core became thicker and the fibrous cap became thinner in the SCD group than in the CHD group $(P<0.05)$. There was no or low expression of ATF3, inflammatory factors, VCAM1 and MMP-9 in the control group, and the expression of inflammatory factors, VCAM1 and MMP-9 in the SCD group was higher than that in CHD group, while the expression of ATF3 in the SCD group was significantly lower than that in CHD group $(P<0.05)$. In the lesion group, the expression of ATF3 was negatively correlated with intimal and necrotic focus thickness, positively correlated with fibrous cap thickness $(P<0.01)$, and negatively correlated with inflammatory factors, VCAM1 and MMP-9 $(P<0.01)$

Conclusions: The expression of ATF3 may be related to the progression and stability of atherosclerotic plaques, and may affect the structural stability of atherosclerotic plaques by regulating the inflammatory response, thus participating in the regulation of atherosclerotic progression. 
Keywords: Atherosclerosis; ATF3; plaque stability; inflammatory reaction; coronary heart disease

\section{Background}

Coronary heart disease (CHD) is the leading cause of death due to noncommunicable diseases worldwide, accounting for $16 \%$ of the total global deaths [1]. Atherosclerosis (AS), the pathological basis of CHD, is considered to be a complex chronic inflammatory disease that occurs in the walls of blood vessels [2]. Many kinds of inflammatory cells, including mononuclear macrophages, are involved in the occurrence and development of AS [3]. However, the aetiology and pathogenesis of CHD are still unclear in clinical medicine and forensic medicine research.

In recent years, dysfunctional cell signal transduction and gene expression have been suggested to be key molecular mechanisms of cardiovascular disease [3-5]. Transcription factors directly affect gene expression and play key roles in regulating cell function and disease development [6]. Activating transcription factor 3 (ATF3), a member of the ATF/cAMP response element binding (CREB) protein family, is important transcription factor $[7,8]$. ATF3 expression level is low in quiescent cells but can be induced in response to various stimuli, such as cytokines and chemokines [9-11]. Studies have shown that ATF3 gene dysfunction is related to many pathophysiological reactions, such as inflammation, signal transmission, apoptosis, oxidative stress and endoplasmic reticulum stress, and ATF3 is involved in a variety 
of pathophysiological changes, such as extracellular matrix dysfunction, smooth muscle cell proliferation and migration, and foam cell formation, in the development of atherosclerosis. However, most of the previous studies were based on serological or animal experiments, and there have been few reports on human atherosclerosis. In this study, coronary arteries from autopsy cases were used to directly examine the degree of inflammation and the expression of ATF3 in human coronary artery lesions and to explore the relationship between the expression of ATF3, the level of inflammation in atherosclerotic plaques and the structural stability of atherosclerotic plaques.

\section{Methods}

\section{Case selection}

Autopsy cases were selected from the Forensic Judicial Expertise Centre of Guizhou Medical University from January 2017 to December 2019. The principles outlined in the Declaration of Helsinki and the Rules for Autopsy issued by the Ministry of Health of the People's Republic of China were followed. It had obtained the informed consent from donor or next of kin of the deceased and was approved by the Ethics Review Committee of Guizhou Medical University (approval number: 201801). Sixty-eight coronary artery tissue specimens were included in the lesion group: including 36 cases of sudden death from coronary heart disease complicated with plaque rupture and intraplaque haemorrhage (SCD group) and 32 cases of acute death caused by mechanical injury with coronary atherosclerosis (CHD group). 
Twenty-two cases of acute death caused by mechanical injury and no coronary heart disease were used as the control group (CON group).

The following inclusion criteria were applied to the disease group. (1) The cadaver was cryopreserved within 6 hours of death, and the autopsy was performed within 48 hours of death. (2) The presence of coronary artery AS was confirmed by the naked eye and histological examination. Coronary artery intimal thickening, lumen narrowing, atherosclerotic plaque formation, atherosclerotic plaque rupture, intraplaque haemorrhage and aneurysm formation were observed in the thickened coronary artery intima, with or without any secondary lesions such as atherosclerotic plaque rupture, intraplaque hemorrhage, aneurysm formation, etc. (3) In CHD group, the cause of death was mechanical violence and died rapidly. (4) In the SCD group, systematic autopsy and routine toxicological examination were performed within 24 hours from the onset of coronary heart disease symptoms to death, excluding the possibility of poisoning or other diseases.

The inclusion criteria of the control group was autopsy at the same time as the disease group, no coronary artery disease as confirmed by the naked eye and histological examination, and that the cause of death was mechanical violence. The exclusion criteria were as follows: (1) tissue autolysis or unclear structure; (2) rheumatic heart disease, cardiomyopathy, myocarditis and other heart disease; and (3) multiple systemic inflammatory infections or multiple organ dysfunction. 
According to the nano-exclusion standard, the left anterior descending coronary artery without any lesion was selected as the control group. The experimental group specimens were selected as the locations at which stenosis of the anterior descending coronary artery was the heaviest as observed by the naked eye, and the selected tissue was fixed with $4 \%$ formaldehyde. Part of the tissue was frozen at $-80{ }^{\circ} \mathrm{C}$ for protein extraction and analysis.

\section{Observation of coronary artery structure}

After the selected coronary artery tissue was fixed with 4\% paraformaldehyde for 72 hours, the cross section of the blood vessel was embedded in paraffin, 4- $\mu \mathrm{m}$ sections were prepared and stained with conventional HE, and an EasyScan digital section scanning and application system (McAudi Industrial Group Co., Ltd., China) was used to observe the morphology and structure of the coronary artery. The intimal thickness (including lesions), fibrous cap thickness, necrotic focus thickness and degree of stenosis in the coronary artery were measured by IPP 6.0. Structural changes in the blood vessels and plaque stability were evaluated comprehensively [13]. Increased intimal thickness was associated with and increased lumen stenosis and worsened atherosclerosis. Thinner fibres and larger necrotic foci were associated with increased atherosclerotic plaque instability.

\section{Immunohistochemical staining}

The expression and distribution of target proteins in coronary artery lesions were analysed by immunohistochemistry (IHC). The coronary artery tissue was stored at 
$4{ }^{\circ} \mathrm{C}$, warmed to room temperature, baked at $60^{\circ} \mathrm{C}$ for 1 hour, and hydrated with concentration gradient after being dewaxed with xylene. Endogenous peroxidase was blocked with $3 \% \mathrm{H} 2 \mathrm{O} 2$, hyperbaric heat repair antigen was performed for 4 min, and the samples were blocked with goat serum and then incubated with antibodies against ATF3 (1:150, ${ }^{\#}$ ab254268, Abcam, UK), CD45 (1:200, " 20103-1-AP, Proteintech, China), IL-1 $\beta$ (1:150, " abs131179, Absin, China), TNF- $\alpha$ (1:100, ${ }^{\#}$ YM3478, Immunoway, China), MMP-9 (1:50, ${ }^{\# 10375-2-A P, ~ P r o t e i n t e c h, ~ C h i n a), ~ a n d ~ V C A M 1 ~}$ (1:200, \#abs119895, Absin, China). PBS was selected as negative control and incubated with the sections overnight in wet box at $4{ }^{\circ} \mathrm{C}$. On the next day, the primary antibody was washed away with PBS, and horseradish peroxidase-labelled sheep anti-rabbit IgG secondary antibody was added. After being incubated for $30 \mathrm{~min}$ at $37^{\circ} \mathrm{C}$, DAB was used for colour development, and the samples were stained with haematoxylin, cleared with xylene and sealed with neutral gum. The positive expression of the target protein was observed under a microscope, and was visualized as a brown colour.Three visual fields were selected and pictures were taken at $400 \times$ magnification. The mean optical density (MOD) of the positive signal was measured by IPP6.0 software to evaluate the degree of target protein expression (MOD= positive expression/total measured area). The result is the average value of 3 repeated measurements.

\section{Western blotting}

Protein expression in the coronary artery was analysed by Western blotting. Vascular tissue was stored at $-80^{\circ} \mathrm{C}$, the homogenate was prepared, and the protein 
concentration was determined by ultraviolet spectrophotometry. SDS gel electrophoresis $(10 \%)$ was performed, the proteins were transferred to a polyvinylidene fluoride membrane, and the membrane was sealed with $5 \%$ skim milk for 2 hours. According to the molecular size of the target protein (ATF3, 1:300; CD45, 1:1000; IL-1 $\beta, 1: 1000$; TNF- $\alpha, 1: 1500$; MMP-9, 1:600; VCAM1, 1:1000), the corresponding PVDF membranes were incubated overnight on a shaker at $4{ }^{\circ} \mathrm{C}$. After the membranes were washed, HRP-conjugated goat ant-rabbit IgG (1:5000, Absin, China) was added and incubated at room temperature for 1 hour. Chemiluminescent HRP substrate (Millipore, USA) was used for colour development on a chemiluminescence imaging system. $\beta$-actin was used as the internal reference, the grey value of the band was analysed and measured by ImageJ, and the mean value of three measurements was taken as the result.

\section{Statistical analysis}

The data were analysed by SPSS 22.0 statistical software, and normal distribution and homogeneity of variance were tested. The measurement data are expressed as the mean $\pm \mathrm{SD}$. The mean of the homogeneity of variance was compared by single factor analysis of variance (LSD), and data with uneven variances were analysed by the Games-Howell test. The chi-square test was used to compare the counting data between the two groups, and correlations were analysed by the Pearson correlation coefficient test. The difference was statistically significant at $P<0.05$ and $P<0.01$. 


\section{Results}

\section{Basic case information}

According to the nano-arrangement standard, 90 coronary artery specimens were collected. There were 22 cases in the control group, including 14 males and 8 females, aged 20 to 78 years old, with an average age of $35.14 \pm 13.63$ years. There were 32 cases in the CHD group, including 14 males and 18 females, aged 30 to 50 years old, with an average age of $38.56 \pm 4.40$ years. There were 36 cases of sudden death from coronary heart disease, including 19 males and 17 females, aged 47 to 74 years old, with an average age of $57.58 \pm 7.18$ years. Comparing the baseline data among the groups, there was no significant sex difference between the groups $(P>0.05)$. There was a significant difference in age among the groups $(P<0.05)$ (Table 1$).$

Table 1. Baseline case information

\begin{tabular}{ccccc}
\hline Group & $\begin{array}{c}\text { Sex } \\
\text { (Male/female) }\end{array}$ & Sum & $\begin{array}{c}\text { Constituent } \\
\text { ratio }(\%)\end{array}$ & Age(year) \\
\hline Con & $14 / 8$ & 22 & 24.44 & $35.14 \pm 13.63$ \\
CHD & $14 / 18$ & 32 & 35.56 & $38.56 \pm 4.40^{\mathrm{a}}$ \\
SCD & $19 / 17$ & 36 & 40.00 & $57.58 \pm 7.18^{\mathrm{ab}}$ \\
Total & - & 90 & 100.00 & - \\
$\chi^{2}$ or $F$ & 2.074 & - & - & 43.438 \\
$P$ & 0.355 & - & - & $<0.001$ \\
\hline
\end{tabular}

${ }^{\mathrm{a}} P<0.01$ VS Con; ${ }^{\mathrm{b}} P<0.01$ VS CHD. 


\section{Morphological observations of the coronary artery}

The histopathological staining results showed that the intimal wall of the coronary artery was thin and smooth, and the thicknesses of the intima, media and adventitia were uniform in the control group. In the CHD group, the intima of the coronary artery exhibited uneven thickening, and the lumen was narrowed to different degrees. Typical fibrous caps were observed under the intima, and atherosclerotic necrotic substances were observed under the fibrous caps in some cases. The media was thinned due to plaque compression and smooth muscle atrophy, and changes in the adventitia were not obvious (Fig. 1).

Image analysis showed that coronary intimal thickness and necrotic focus thickness in the lesion group were higher than those in the control group, the thickness of the fibrous cap decreased and the degree of lumen stenosis increased in the lesion group $(P<0.05)$. Compared with those of the CHD group, the thickness of the coronary intima, the thickness of the necrotic focus and the degree of stenosis in the SCD group were increased, and the thickness of the fibrous cap was reduced $(P<$ 0.05) (Table 2). 

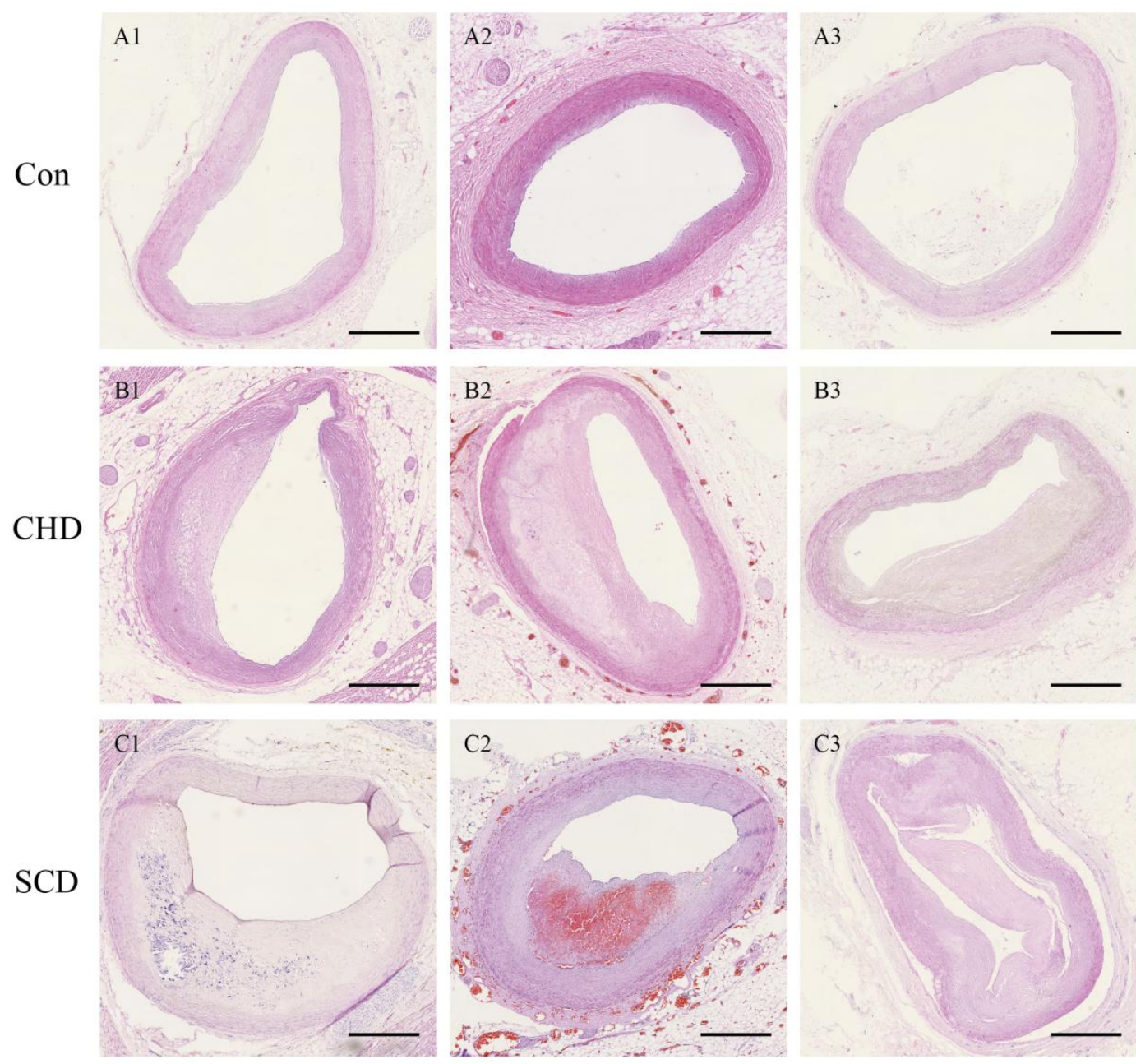

Figure 1. Microscopic changes in coronary atherosclerosis. A1-A3 Control group, Con. B1-B3 Coronary heart disease group, CHD. C1-C3 Sudden death due to coronary heart disease with intraplaque bleeding and rupture group, SCD. (HE staining, scale bar $=1 \mathrm{~mm}$ ) 
Tab 2. Comparison of morphological indexes of coronary artery lesions

$(\operatorname{mean} \pm \mathbf{S D})$

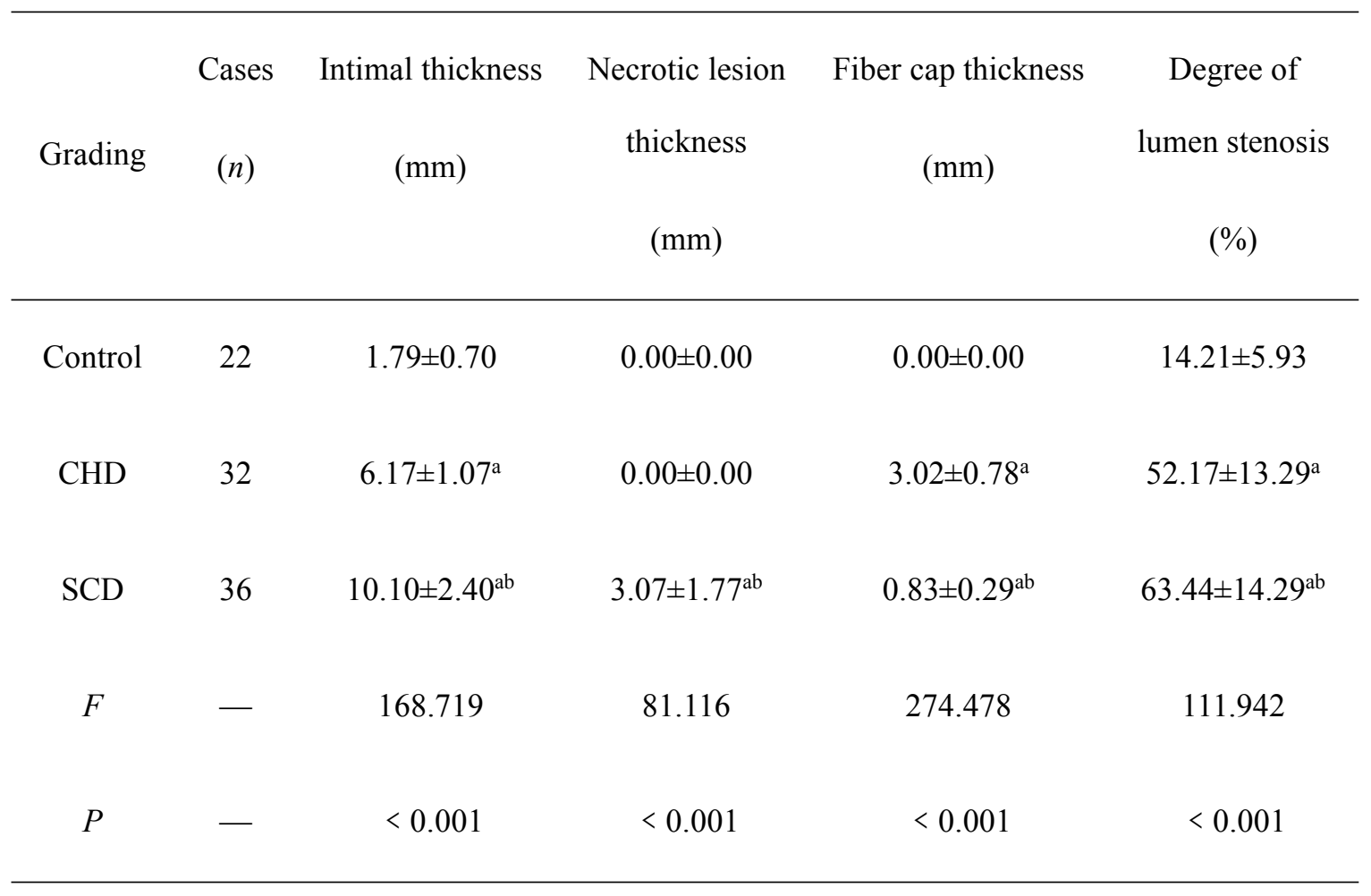

${ }^{\mathrm{a}} P<0.05$ vs control; $\mathrm{b} P<0.05$ vs CHD.

\section{ATF3 protein expression in coronary atherosclerotic lesions}

The Western blot results showed that the expression of ATF3 in coronary artery tissue in the lesion group was higher than that in the control group, and the expression of ATF3 in the SCD group was lower than that in the CHD group (Fig. 2A-B, $P$ $<0.01)$. The immunohistochemical results showed that there was no positive expression of ATF3 in the control group, but ATF3 was expressed in the cytoplasm and nucleus of foam cells in the shoulder area and bottom of the atherosclerotic focus in the disease group, as indicated by yellow or brown staining (Fig. 2C). The optical density was measured by IPP6.0 and showed that the MOD in the disease group was 
higher than that in the control group, while the MOD in the SCD group was significantly lower than that in the CHD group (Fig. $2 \mathrm{D}, P<0.01$ ).

A

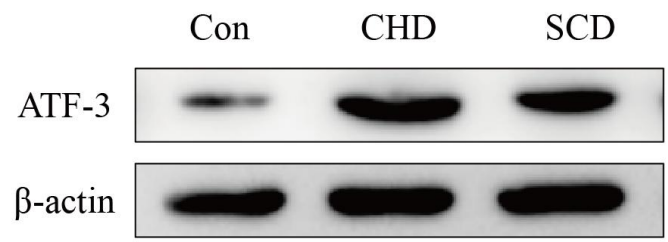

$21 \mathrm{kD}$

$43 \mathrm{kD}$
$\mathrm{B}$

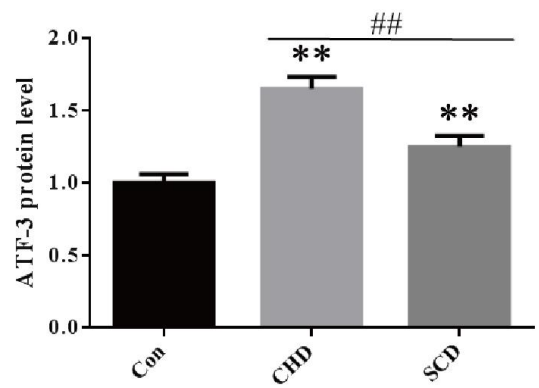

C

Con

CHD

SCD

ATF3
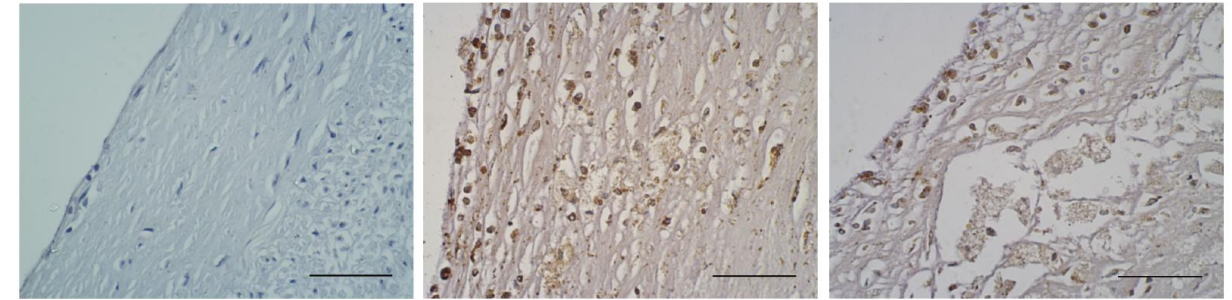

$\mathrm{D}$

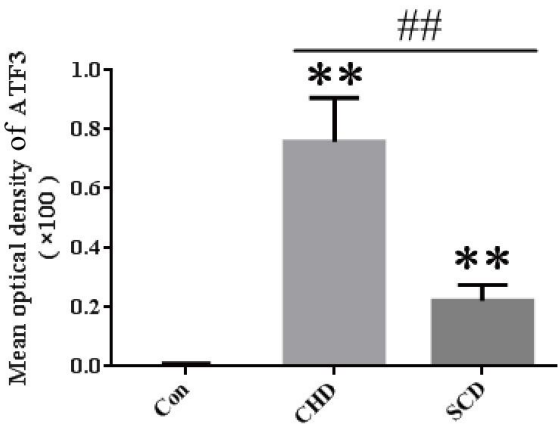

Figure 2. ATF3 expression levels in the coronary artery. A-B Representative Western blot images and quantitative analysis of ATF3 expression levels. C-D Representative immunohistochemical images and quantitative analysis of ATF3 expression in each group (scale bar $=50 \mu \mathrm{m}$ ). All experiments were repeated at least three times. The data are expressed as the mean $\pm \mathrm{SD}(\mathrm{n}=12$ per group). ${ }^{* *} P<0.01$ vs the control group; \#\#P<0.01 vs the CHD group

\section{Expression of CD45, IL-1 $\beta$ and TNF- $\alpha$ in the coronary artery}


The Western blot results showed that the levels of CD45, IL-1 $\beta$ and TNF- $\alpha$ in the lesion group were higher than those in the control group, and the expression of proteins in the SCD group was higher than that in the CHD group (Fig. 3A-B, $P$ $<0.05)$. The immunohistochemistry results also showed that there was no expression of inflammatory factors in the intima in the control group, but in the atherosclerotic lesions, CD45 was expressed on the membrane of inflammatory cells in the shoulder area and the bottom of the lesions. IL-1 $\beta$ and TNF- $\alpha$ were mainly expressed in the cytoplasm and nuclei of foam cells around the atherosclerotic lesions, as indicated by yellow or brown staining (Fig. 3C). The mean density was measured by IPP6.0 and showed that positive expression in the lesion group was significantly higher than that in the control group, while positive expression in the SCD group was significantly higher than that in the CHD group, and the difference was statistically significant (Fig. $3 \mathrm{D}, P<0.01)$. 
A

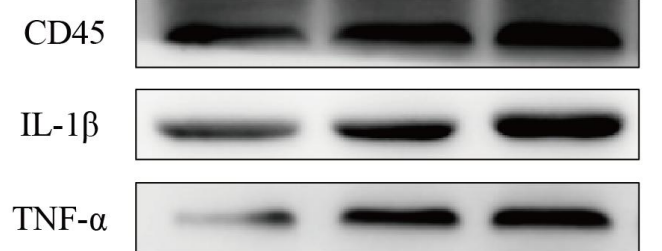

$\beta$-actin

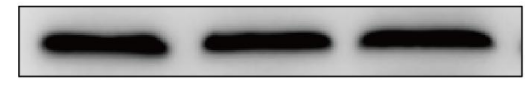

C
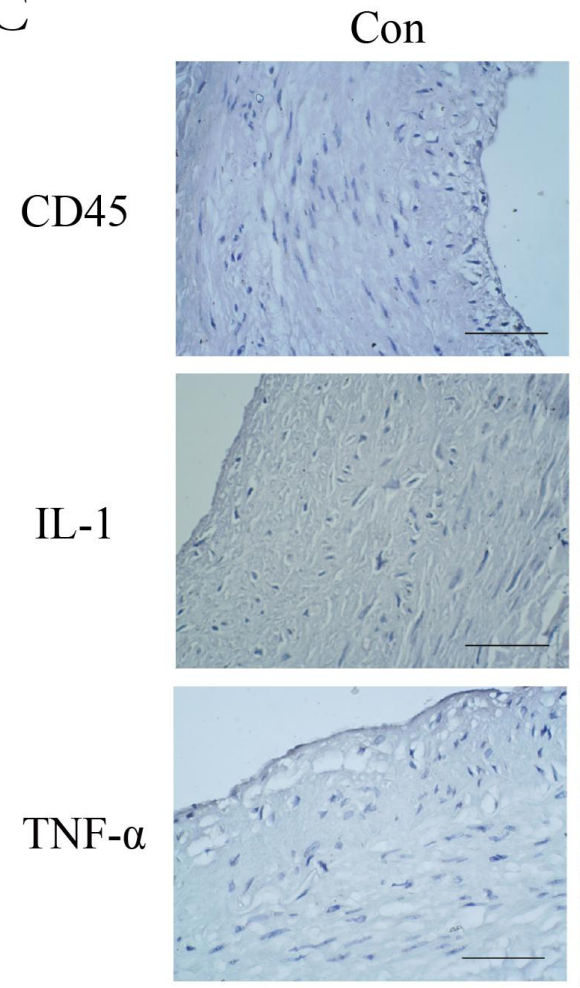

$200 \mathrm{kD}$

$31 \mathrm{kD}$

$25 \mathrm{kD}$

$43 \mathrm{kD}$

CHD
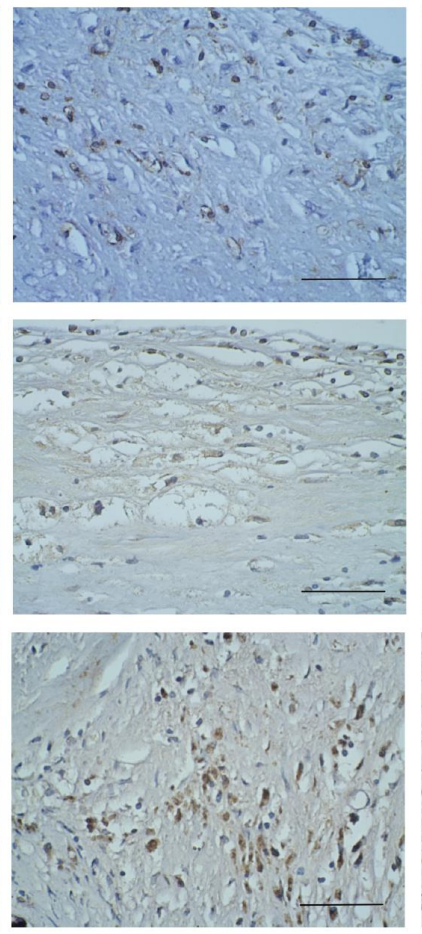

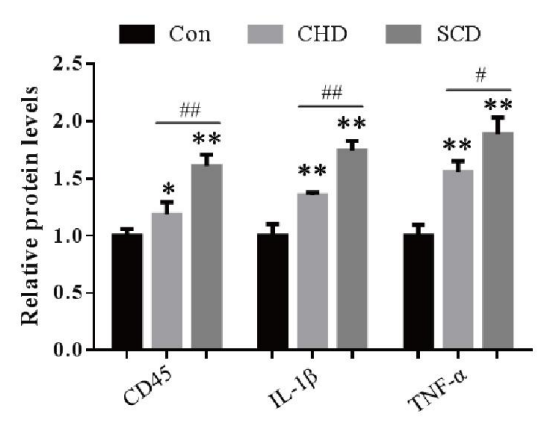

SCD
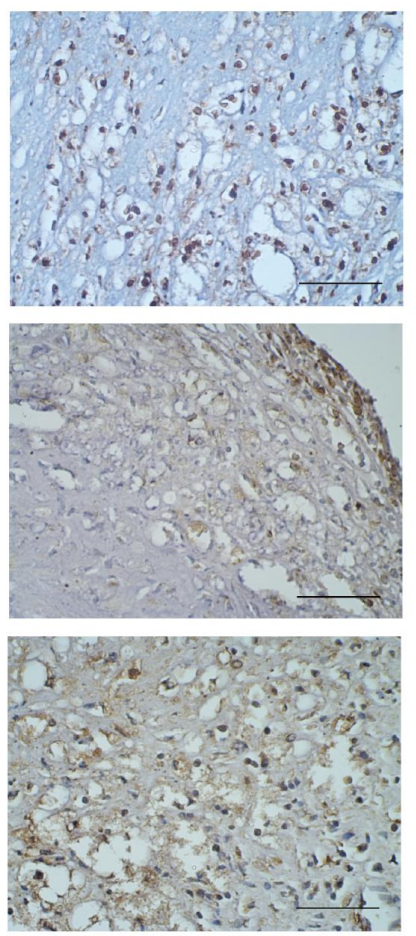

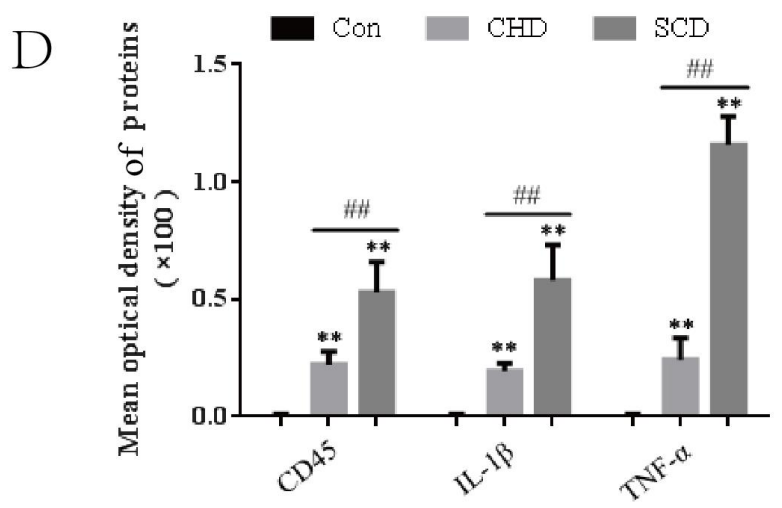

Figure 3. Protein expression levels in the coronary artery. A-B Representative Western blot

images and quantitative analysis of protein expression levels. C-D Representative

immunohistochemical images and quantitative analysis of protein expression in each group (scale 
bar $=50 \mu \mathrm{m})$. All experiments were repeated at least three times. The data are expressed as the mean $\pm \mathrm{SD}$ ( $\mathrm{n}=12$ per group). ${ }^{*} P<0.05$ vs the control group; ${ }^{* *} P<0.01$ vs the control group; \#\#P< 0.01 vs the CHD group

\section{Expression of VCAM1 and MMP-9 in the coronary artery}

The Western blot results showed that the expression of VCAM1 and MMP-9 in the lesion group was higher than that in the control group, and the expression of proteins in the SCD group was higher than that in the CHD group (Fig. 4 A-B, $P$ $<0.05)$. The immunohistochemistry results showed that there was no positive expression of VCAM1 or MMP-9 in the control group, but VCAM1 expression was found in vascular endothelial cells and subendothelial foam cells in both the CHD and SCD groups, while MMP-9 was mainly expressed in the cytoplasm of inflammatory cells in the shoulder area and bottom of the lesion, as indicated by yellow or brown staining of some nuclei (Fig. 4 C). The optical density was measured by IPP6.0 and showed that positive expression in the lesion group was significantly higher than that in the control group, while positive expression in the SCD group was significantly higher than that in the CHD group, and the difference was statistically significant (Fig. $4 \mathrm{D}, P<0.01)$. 
A

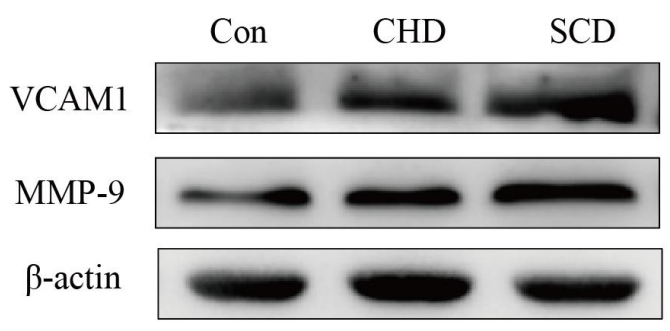

C
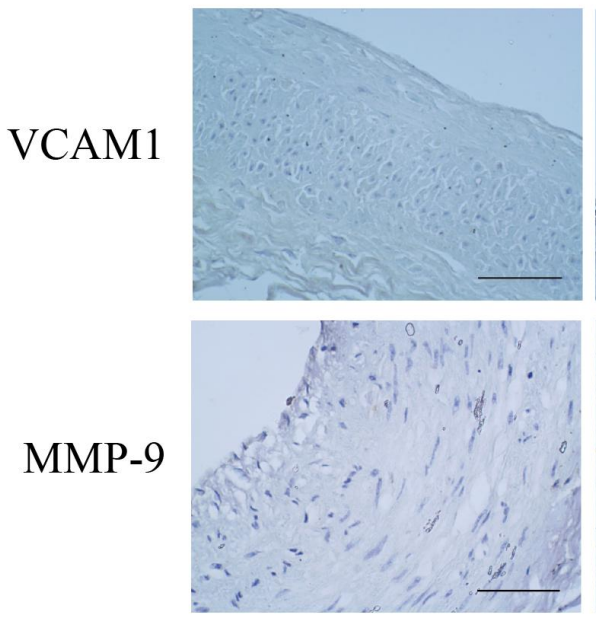

B

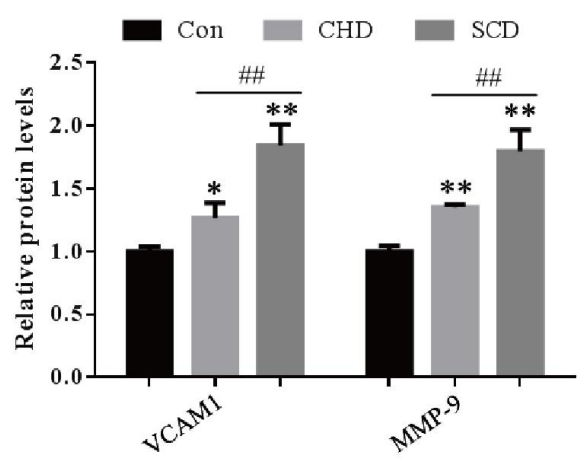

$81 \mathrm{kD}$

$67 \mathrm{kD}$

$43 \mathrm{kD}$

SCD
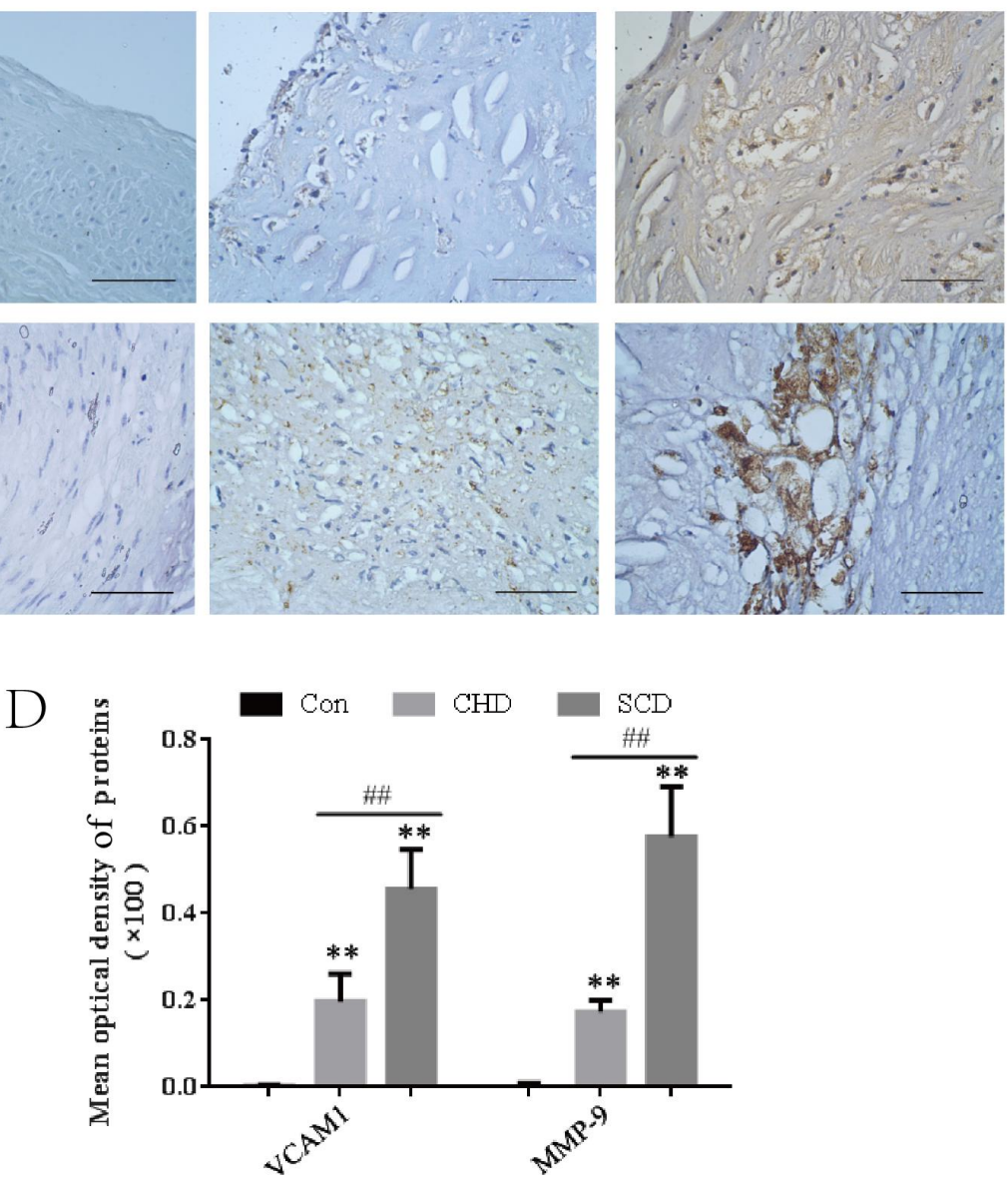

Figure 4. Protein expression levels in the coronary artery. A-B Representative Western blot images and quantitative analysis of protein expression levels. C-D Representative immunohistochemical images and quantitative analysis of protein expression in each group (scale bar $=50 \mu \mathrm{m})$. All experiments were repeated at least three times. The data are expressed as the mean $\pm \mathrm{SD}$ ( $\mathrm{n}=12$ per group). $* P<0.05$ vs the control group; $* * P<0.01$ vs the control group; \#\#P< 


\section{Correlation analysis of ATF3 protein expression in AS lesions and the structural} indexes of the lesions

The correlations between the protein level of ATF3 in AS lesions and coronary intimal thickness, necrotic lesion thickness, fibre cap thickness and degree of lumen stenosis were analysed. The results showed that the protein level of ATF3 in atherosclerotic lesions was negatively correlated with coronary intimal thickness and necrotic lesion thickness $(P<0.01$, Fig. $5 \mathrm{~A} / \mathrm{C})$ and positively correlated with fibrous cap thickness $(P<0.01$, Fig. 5 B) but did not correlate with the degree of lumen stenosis $(P>0.05)$.

A

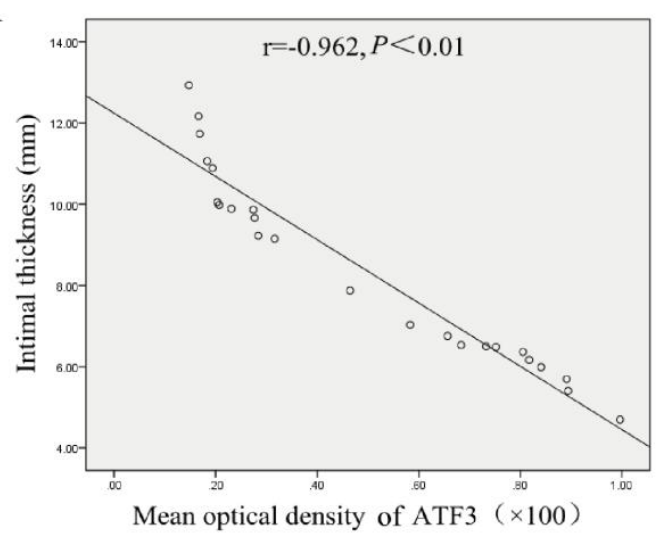

B

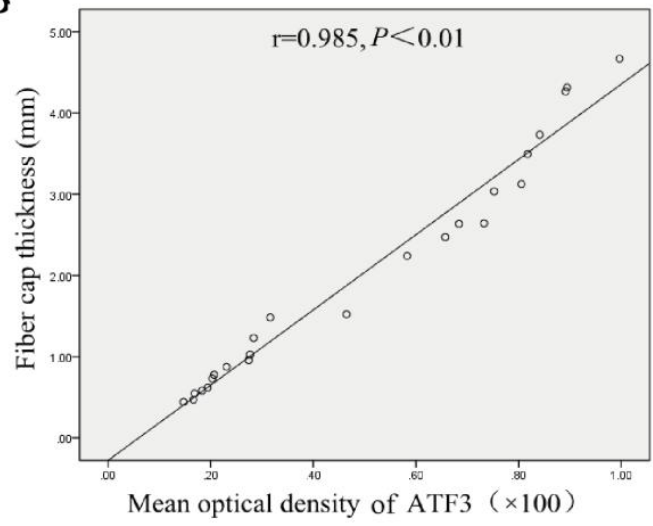

$\mathrm{C}$

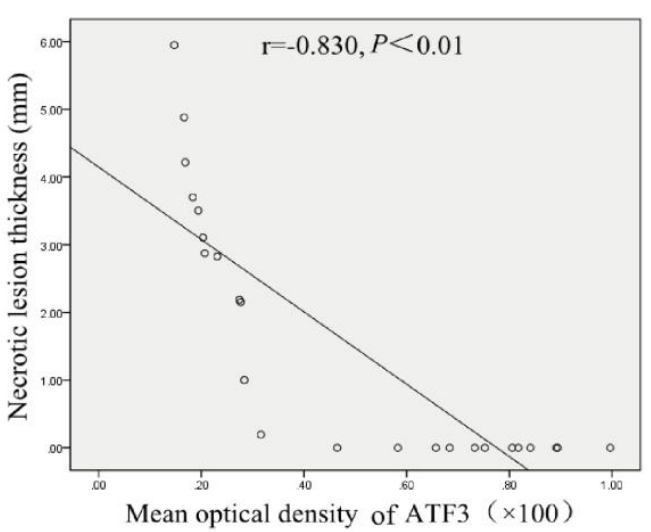

Figure 5. Correlations between the protein level of ATF3 and the structural indexes of the lesion 
in the lesion group. A-C Intimal thickness, fibrous cap thickness, and necrotic lesion thickness. r: Spearman's correlation coefficient. $P<0.01$ was considered to indicate a significant correlation.

\section{Correlation analysis of ATF3 protein expression and inflammation in AS lesions}

The correlations between the protein level of ATF3 in atherosclerotic plaques and the inflammatory factors CD45, IL- $1 \beta$ and TNF- $\alpha$ showed that ATF3 was negatively correlated with these factors ( $P<0.01$, Fig. 6 A-C).

A

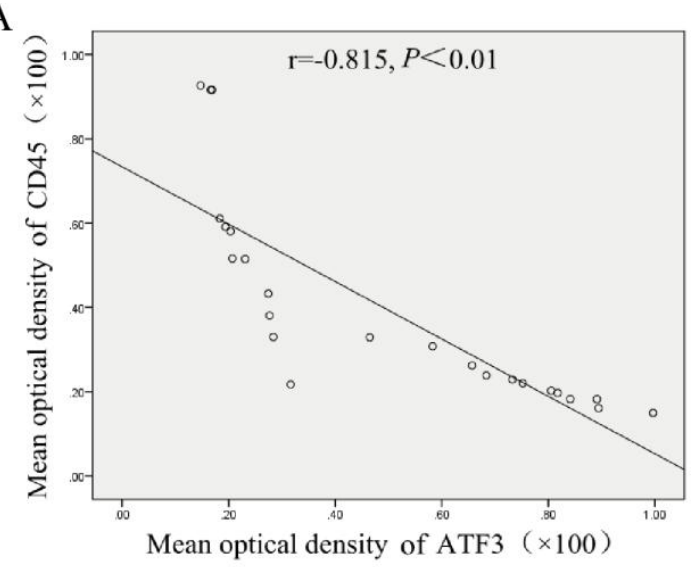

B

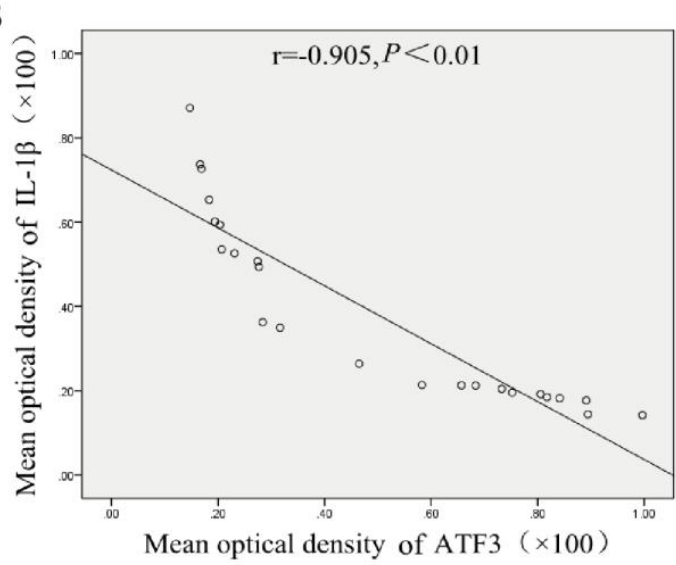

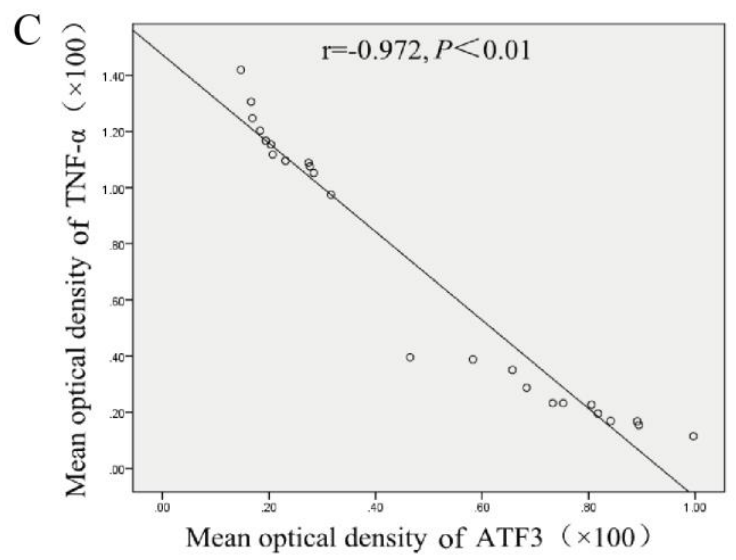

Figure 6. The correlation between ATF3 protein levels and inflammatory factors in the lesion group. r: Spearman's correlation coefficient. A-C CD45, IL-1 $\beta$, and TNF- $\alpha . P<0.01$ was considered to indicate a significant correlation. 
Correlation analysis of ATF3 protein expression and MMP-9 and VCAM1 levels in AS lesions

Correlation analysis of the protein expression level of ATF3 and MMP-9 and VCAM1 showed that ATF3 was negatively correlated with both of factors $(P<0.01$, Fig. 7 A-B).
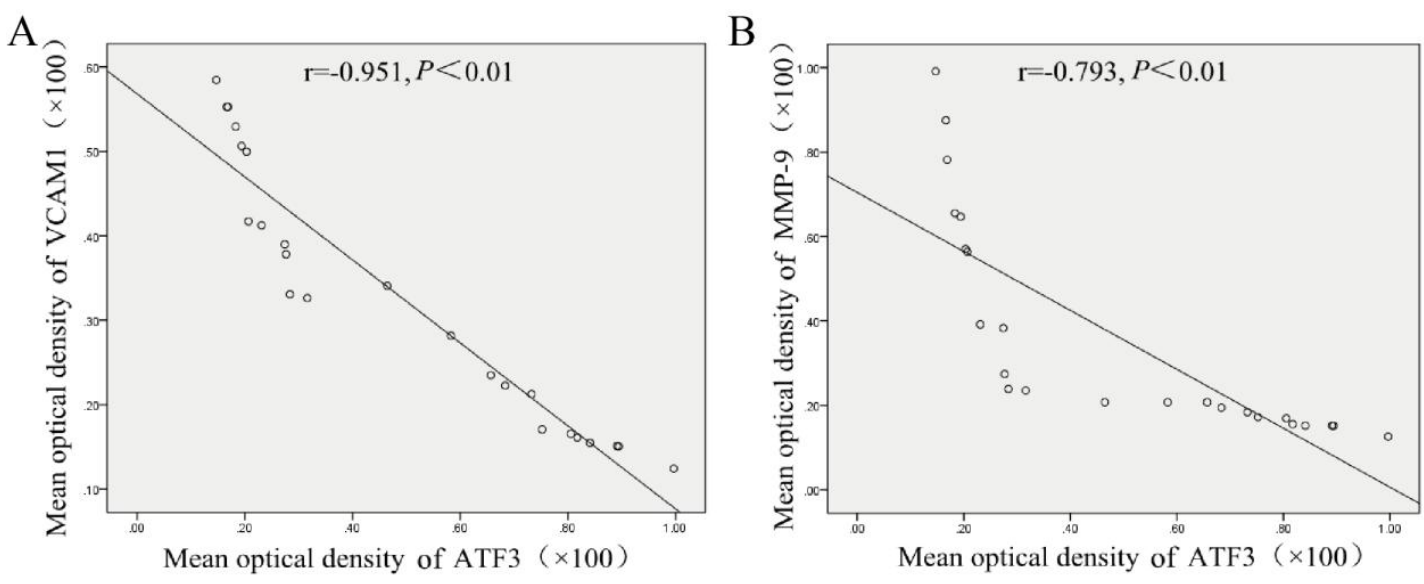

Figure 7. The correlation between ATF3 protein levels and VCAM1 and MMP-9 in the lesion group. r: Spearman's correlation coefficient. A-B VCAM1, MMP-9. P $<0.01$ was considered to indicate a significant correlation.

\section{Discussion}

The occurrence of sudden death due to CHD is closely related to the structural stability of atherosclerotic plaques [14-15], but the factors affecting the stability of atherosclerotic plaques are still unclear. Research has shown that inflammation is a key factor that affects plaque stability [16]. In the pathogenesis of atherosclerosis, a variety of white blood cells, including monocytes, deposit under the intima and take up lipoproteins such as low-density lipoprotein and very-low-density lipoprotein to 
form foam cells [17]. They induce a serious inflammatory cascade, leading to vascular stenosis, intraplaque haemorrhage, plaque rupture and other secondary lesions, which can cause sudden death.

Plaque stability is closely related to the onset of coronary heart disease and sudden death, and a consensus has gradually been reached that inflammation is a key factor in plaque. CD45 is expressed on the membranes of all inflammatory cells and is considered to be a marker of inflammation [18]. Both IL-1 $\beta$ and TNF- $\alpha$ are proinflammatory factors produced by inflammatory cells that mainly mediate the human immune and inflammatory responses [19-21]. Studies have shown that inflammation plays an important role in the occurrence and development of atherosclerosis. Activated leukocytes can adhere and accumulate in the vascular endothelium. and continue to release a variety of enzymes, cytokines and growth factors, resulting in persistent damage to blood vessels [22]. Targeted inhibition of inflammatory cytokines such as IL-1 $\beta$ and TNF- $\alpha$ has gradually become a new therapeutic strategy against atherosclerotic vascular diseases [24-26]. Our study shows that the expression levels of CD45, IL-1 $\beta$ and TNF- $\alpha$ are significantly increased in human coronary atherosclerotic lesions, which indicates that inflammation plays an important role in atherosclerosis. Our study showed that the expression of CD45, IL-1 $\beta$ and TNF- $\alpha$ in atherosclerotic lesions in the SCD group was higher than that in the CHD group, suggesting that exacerbation of the inflammatory response was closely related to plaque instability.

Endothelial dysfunction is considered an early indicator of atherosclerosis and is 
characterized by the overexpression of adhesion molecules, including intercellular adhesion molecule-1 (ICAM-1) and vascular cell adhesion molecule-1 (VCAM-1) [27]. VCAM-1 mediates the rolling and adhesion of leukocytes, recruits leukocytes from the blood, and promotes monocytes to enter the vascular intima and express a variety of inflammatory cytokines after activation. The upregulated expression of VCAM-1 is considered to be a risk factor for plaque instability and myocardial infarction [28]. In late atherosclerotic lesions, the expression of MMP-9 is increased and can induce plaque destruction [29]. Volkov et al. [30] also confirmed that the level of MMP-9 was significantly increased in unstable fatty plaques, necrotic plaques and inflammatory erosive plaques. These studies suggest that VCAM-1 and MMP-9 play important early warning roles in unstable plaques. In our study, the expression of VCAM-1 and MMP-9 was increased in endothelial and subendothelial foam cells in the atherosclerotic group, especially in the SCD group, and the expression levels of VCAM-1 and MMP-9 in the atherosclerotic group were significantly higher than those in the CHD group, further suggesting that the increased expression of VCAM-1 and MMP-9 in the lesion could promote monocytes and other inflammatory cells to adhere to the endothelium, become activated and release a large number of inflammatory cytokines. Promoting the degradation of collagen in plaques leads to a decrease in plaque stability and the occurrence of sudden death.

Gold et al. showed that ATF3 was the key factor in lipid metabolism and the inflammation pathway in these cells that prevented atherosclerosis by inhibiting the formation of liposomes induced by 25-hydroxy. By analysing the atherosclerotic data 
set from the NCBI-Gene Expression Omnibus database, it was found that the expression level of ATF3 in macrophages in ruptured atherosclerotic plaques was lower than that in stable atherosclerotic plaques, and it was further confirmed in animal experiments that a lack of ATF3 and an increase in macrophages may be risk factors for atherosclerotic plaque rupture [32]. The results of the present study showed that the expression level of ATF3 increased significantly in human coronary atherosclerotic plaques but decreased in the SCD group. By analysing the correlation between ATF3 expression and coronary artery structural indexes, it was found that ATF3 negatively correlated with coronary artery intimal thickness, necrotic core thickness and organ stenosis and positively correlated with fibrous cap thickness, intimal and dead focus thickening and fibre thickening. This finding indicates suggests that the expression of ATF3 may be related to the progression and stability of atherosclerotic plaques.

Malpass et al. [33] analysed the differential gene expression of human microvascular endothelial cells (HMEC-1) induced by cisplatin using the gene chip dataset GSE62523 and found that both ATF3 and VCAM1 may be key genes associated with endothelial injury. High-density lipoprotein (HDL) exerts protects the vasculature by promoting the activation of transcription factors (such as ATF3), resulting in downregulation of the inflammatory response induced by Toll-like receptors (TLRs) [34]. Targeted knockout of the ATF3 gene exacerbated cerebral ischaemia-reperfusion injury, significantly increased the expression of VCAM1 and MMP-9 [35], induced VSMC apoptosis and regulated the survival rates of vascular 
smooth muscle cells [36]. We analysed the correlation between ATF3, VCAM1 and MMP-9, and the results showed that there was a negative correlation between VCAM-1 and MMP-9. The important early warning role of VCAM1 and MMP-9 in unstable plaques further suggests that the occurrence of unstable atherosclerotic plaques may be related to the decrease in ATF3 levels. Related studies have shown that under the stimulation of various stress signals, ATF3 transcription activates many

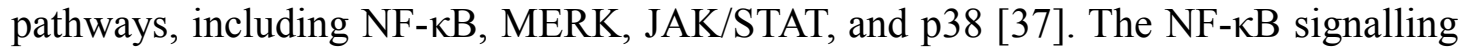
pathway plays a key role in regulating the inflammatory response in atherosclerosis. Phosphorylated NF- $\mathrm{BB}$ promotes the expression of many inflammatory genes, including VCAM-1, MCP-1, TNF- $\alpha$, IL-1 $\beta$ and IL-6 [38]. The indirect interaction between ATF3 and NF- $\mathrm{BB}$ has been confirmed in lipopolysaccharide-activated macrophages and a renal ischaemia-reperfusion model [39]. Some studies have shown that ATF3 inhibits inflammation by directly interacting with the p65 subunit of NF- $\mathrm{BB}$ [40]. Therefore, we hypothesize that ATF3 may affect the stability of atherosclerotic plaques by regulating the inflammatory response.

\section{Conclusions}

In summary, our study shows that in atherosclerosis, the degree of inflammatory reaction in plaques is related to plaque stability, the expression of ATF3 may be related to the progression and stability of atherosclerotic plaques, and may affect the structural stability of atherosclerotic plaques by regulating the inflammatory response in atherosclerotic plaques. 
The current evidence shows that ATF3 can regulate cell dysfunction, such as apoptosis and inflammation, but whether ATF3 is a mediating factor or an inhibitory factor is still unclear, and the specific mechanism of ATF3 in atherosclerosis is still unclear. Therefore, we will use animal and cell models to further verify whether the deletion or overexpression of ATF3 depends on the NF- $\mathrm{kB}$ signalling pathway to regulate the inflammatory response in atherosclerosis.

\section{Abbreviations}

ATF3: Activating transcription factor 3 ; CHD: Coronary Heart Disease ; SCD: Sudden cardiac death; AS: Atherosclerosis; CD45: Leukocyte common antigen; IL-1 $\beta$ : Lnterleukin-1 $\beta$; TNF- $\alpha$ : Tumor necrosis factor $\alpha$; MMP-9: Matrix metalloproteinase-9; VCAM1: Vascular cell adhesion molecule 1.

\section{Ethics approval and consent to participate}

The principles outlined in the Declaration of Helsinki and the Rules for Autopsy issued by the Ministry of Health of the People's Republic of China were followed. It had obtained the informed consent from donor or next of kin of the deceased and was approved by the Ethics Review Committee of Guizhou Medical University (approval number: 201801).

\section{Consent for publication}

Not applicable. 


\section{Availability of data and materials}

The datasets generated and analysed during the current study are not publicly available due the principle of funding confidentiality but are available from the corresponding author upon reasonable request.

\section{Competing interests}

The authors declare that there are no conflicts of interest.

\section{Funding}

The study was supported by the National Nature Science Foundation of China (No. 82060340), the Guizhou Province Engineering Technology Research Center Project (Qian High-Tech of Development and Reform Commission No. [2016]1345), the Development Project of Young Scientific and Technological Talents in Colleges and Universities of Guizhou Province [Guizhou Education Cooperation KY (2021)157].

\section{Authors' contributions}

C.W. Wan, J. Wang and J. Peng designed experiments, and wrote the manuscript. B. Xia, J.J. Liu, Z. Li and Q.J. Zhang participated in the collection of human coronary artery specimens. J. Peng and Q. Zhang completed pathological experiment and protein experiment. C.Y. Le and J.W. Wang revised and polished the manuscript. All authors read and approved the final manuscript.

\section{Acknowledgments}


Not applicable.

\section{Author details}

1 Department of Forensic Medicine, Guizhou Medical University, Guizhou Guiyang 550004, China.

\section{References}

1. Zanoli L, Briet M, Empana JP, et al.. Vascular consequences of inflammation: a position statement from the ESH Working Group on Vascular Structure and Function and the ARTERY Society. J Hypertens. 2020 Sep;38(9):1682-1698.

2. Katsuki S, Matoba T, Nakashiro S, Sato K, Koga J, Nakano K, Nakano Y, Egusa S, Sunagawa K, Egashira K. Nanoparticle-mediated delivery of pitavastatin inhibits atherosclerotic plaque destabilization/rupture in mice by regulating the recruitment of inflammatory monocytes. Circulation. 2014 Feb 25;129(8):896-906.

3. Akazawa H. Mechanisms of Cardiovascular Homeostasis and PathophysiologyFrom Gene Expression, Signal Transduction to Cellular Communication. Circ J. 2015;79(12):2529-2536.

4. Ghigo A, Laffargue M, Li M, Hirsch E. PI3K and Calcium Signaling in Cardiovascular Disease. Circ Res. 2017 Jul 21;121(3):282-292.

5. Russo I, Frangogiannis NG. Diabetes-associated cardiac fibrosis: Cellular effectors, molecular mechanisms and therapeutic opportunities. J Mol Cell Cardiol. 2016 Jan;90:84-93. 
6. Bauer AJ, Martin KA. Coordinating Regulation of Gene Expression in Cardiovascular Disease: Interactions between Chromatin Modifiers and Transcription Factors. Front Cardiovasc Med. 2017 Apr 6;4:19.

7. Hai T, Wolfgang CD, Marsee DK, Allen AE, Sivaprasad U. ATF3 and stress responses. Gene Expr. 1999;7(4-6):321-335.

8. Thompson MR, Xu D, Williams BR. ATF3 transcription factor and its emerging roles in immunity and cancer. J Mol Med (Berl). 2009 Nov;87(11):1053-1060.

9. Hai T, Curran T. Cross-family dimerization of transcription factors Fos/Jun and ATF/CREB alters DNA binding specificity. Proc Natl Acad Sci U S A. 1991 May 1;88(9):3720-3724.

10. Hai T, Wolford CC, Chang YS. ATF3, a hub of the cellular adaptive-response network, in the pathogenesis of diseases: is modulation of inflammation a unifying component? Gene Expr. 2010;15(1):1-11.

11. Lu D, Wolfgang CD, Hai T. Activating transcription factor 3, a stress-inducible gene, suppresses Ras-stimulated tumorigenesis. J Biol Chem. 2006 Apr 14;281(15):10473-10481.

12. Zhou H, Li N, Yuan Y, Jin YG, Guo H, Deng W, Tang QZ. Activating transcription factor 3 in cardiovascular diseases: a potential therapeutic target. Basic Res Cardiol. 2018 Aug 9;113(5):37.

13. Wang Y, Sun X, Xia B, et al. The role of OX40L and ICAM-1 in the stability of 
coronary atherosclerotic plaques and their relationship with sudden coronary death. BMC Cardiovasc Disord. 2019;19(1):272.

14. Sakakura K, Nakano M, Otsuka F, Ladich E, Kolodgie FD, Virmani R. Pathophysiology of atherosclerosis plaque progression. Heart Lung Circ. 2013 Jun;22(6):399-411.

15. Davies MJ. Stability and instability: two faces of coronary atherosclerosis. The Paul Dudley White Lecture 1995. Circulation. 1996 Oct 15;94(8):2013-2020.

16. Bäck M, Yurdagul A Jr, Tabas I, Öörni K, Kovanen PT. Inflammation and its resolution in atherosclerosis: mediators and therapeutic opportunities. Nat Rev Cardiol. 2019 Jul;16(7):389-406.

17. Yu M, Tsai SF, Kuo YM. The Therapeutic Potential of Anti-Inflammatory Exerkines in the Treatment of Atherosclerosis. Int J Mol Sci. 2017 Jun 13;18(6):1260.

18. Rafferty AR, D'Arcy C, Cann L, Pyman J, Rogers P, Davis PG, Nowell C, Burgner D. Histological changes in the umbilical artery following severe chorioamnionitis and funisitis may be indicative of early atherosclerosis. Placenta. $2017 \mathrm{Feb} ; 50: 40-43$

19. Libby P. Interleukin-1 Beta as a Target for Atherosclerosis Therapy: Biological Basis of CANTOS and Beyond. J Am Coll Cardiol. 2017 Oct 31;70(18):2278-2289.

20. Williams JW, Huang LH, Randolph GJ. Cytokine Circuits in Cardiovascular Disease. Immunity. 2019 Apr 16;50(4):941-954. 
21. Oberoi R, Vlacil AK, Schuett J, Schösser F, Schuett H, Tietge UJF, Schieffer B, Grote K. Anti-tumor necrosis factor- $\alpha$ therapy increases plaque burden in a mouse model of experimental atherosclerosis. Atherosclerosis. 2018 Oct;277:80-89.

22. Raffel OC, Tearney GJ, Gauthier DD, Halpern EF, Bouma BE, Jang IK.

Relationship between a systemic inflammatory marker, plaque inflammation, and plaque characteristics determined by intravascular optical coherence tomography. Arterioscler Thromb Vasc Biol. 2007 Aug;27(8):1820-1827.

23. Geovanini GR, Libby P. Atherosclerosis and inflammation: overview and updates. Clin Sci (Lond). 2018 Jun 21;132(12):1243-1252.

24. Kirii H, Niwa T, Yamada Y, Wada H, Saito K, Iwakura Y, Asano M, Moriwaki H, Seishima M. Lack of interleukin-1beta decreases the severity of atherosclerosis in ApoE-deficient mice. Arterioscler Thromb Vasc Biol. 2003 Apr 1;23(4):656-660.

25. Bhaskar V, Yin J, Mirza AM, Phan D, Vanegas S, Issafras H, Michelson K, Hunter JJ, Kantak SS. Monoclonal antibodies targeting IL-1 beta reduce biomarkers of atherosclerosis in vitro and inhibit atherosclerotic plaque formation in Apolipoprotein E-deficient mice. Atherosclerosis. 2011 Jun;216(2):313-320.

26. Oberoi R, Vlacil AK, Schuett J, Schösser F, Schuett H, Tietge UJF, Schieffer B, Grote K. Anti-tumor necrosis factor- $\alpha$ therapy increases plaque burden in a mouse model of experimental atherosclerosis. Atherosclerosis. 2018 Oct;277:80-89.

27. Habas K, Shang L. Alterations in intercellular adhesion molecule 1 (ICAM-1) and vascular cell adhesion molecule 1 (VCAM-1) in human endothelial cells. Tissue Cell. 
2018 Oct;54:139-143.

28. Radecke CE, Warrick AE, Singh GD, Rogers JH, Simon SI, Armstrong EJ.

Coronary artery endothelial cells and microparticles increase expression of VCAM-1 in myocardial infarction. Thromb Haemost. 2015 Mar;113(3):605-616.

29. Gough PJ, Gomez IG, Wille PT, Raines EW. Macrophage expression of active MMP-9 induces acute plaque disruption in apoE-deficient mice. J Clin Invest. 2006 Jan;116(1):59-69.

30. Volkov AM, Murashov IS, Polonskaya YV, Savchenko SV, Kazanskaya GM, Kliver EE, Ragino YI, CHernyavskiy AM. [Changes of Content of Matrix Metalloproteinases and Their Tissue Expression in Various Types of Atherosclerotic Plaques]. Kardiologiia. 2018 Oct;(10):12-18.

31. Gold ES, Ramsey SA, Sartain MJ, Selinummi J, Podolsky I, Rodriguez DJ, Moritz RL, Aderem A. ATF3 protects against atherosclerosis by suppressing 25-hydroxycholesterol-induced lipid body formation. J Exp Med. 2012 Apr 9;209(4):807-817.

32. Qin W, Yang H, Liu G, Bai R, Bian Y, Yang Z, Xiao C. Activating transcription factor 3 is a potential target and a new biomarker for the prognosis of atherosclerosis. Hum Cell. 2021 Jan;34(1):49-59.

33. Malpass GE, Arimilli S, Prasad GL, Howlett AC. Regulation of gene expression by tobacco product preparations in cultured human dermal fibroblasts. Toxicol Appl Pharmacol. 2014 Sep 1;279(2):211-219. 
34. Smith CK, Seto NL, Vivekanandan-Giri A, Yuan W, Playford MP, Manna Z, Hasni SA, Kuai R, Mehta NN, Schwendeman A, Pennathur S, Kaplan MJ. Lupus high-density lipoprotein induces proinflammatory responses in macrophages by binding lectin-like oxidised low-density lipoprotein receptor 1 and failing to promote activating transcription factor 3 activity. Ann Rheum Dis. 2017 Mar;76(3):602-611.

35. Wang L, Deng S, Lu Y, Zhang Y, Yang L, Guan Y, Jiang H, Li H. Increased inflammation and brain injury after transient focal cerebral ischemia in activating transcription factor 3 knockout mice. Neuroscience. 2012 Sep 18;220:100-108.

36. Lv D, Meng D, Zou FF, Fan L, Zhang P, Yu Y, Fang J. Activating transcription factor 3 regulates survivability and migration of vascular smooth muscle cells. IUBMB Life. 2011 Jan;63(1):62-69.

37. Rohini M, Haritha Menon A, Selvamurugan N. Role of activating transcription factor 3 and its interacting proteins under physiological and pathological conditions. Int J Biol Macromol. 2018 Dec;120(Pt A):310-317.

38. Wang L, Deng S, Lu Y, Zhang Y, Yang L, Guan Y, Jiang H, Li H. Increased inflammation and brain injury after transient focal cerebral ischemia in activating transcription factor 3 knockout mice. Neuroscience. 2012 Sep 18;220:100-108.

39. Gilchrist M, Thorsson V, Li B, Rust AG, Korb M, Roach JC, Kennedy K, Hai T, Bolouri H, Aderem A. Systems biology approaches identify ATF3 as a negative regulator of Toll-like receptor 4. Nature. 2006 May 11;441(7090):173-178.

40. Kwon JW, Kwon HK, Shin HJ, Choi YM, Anwar MA, Choi S. Activating 
transcription factor 3 represses inflammatory responses by binding to the p65 subunit of NF-кB. Sci Rep. 2015 Sep 28;5:14470. 
Figures

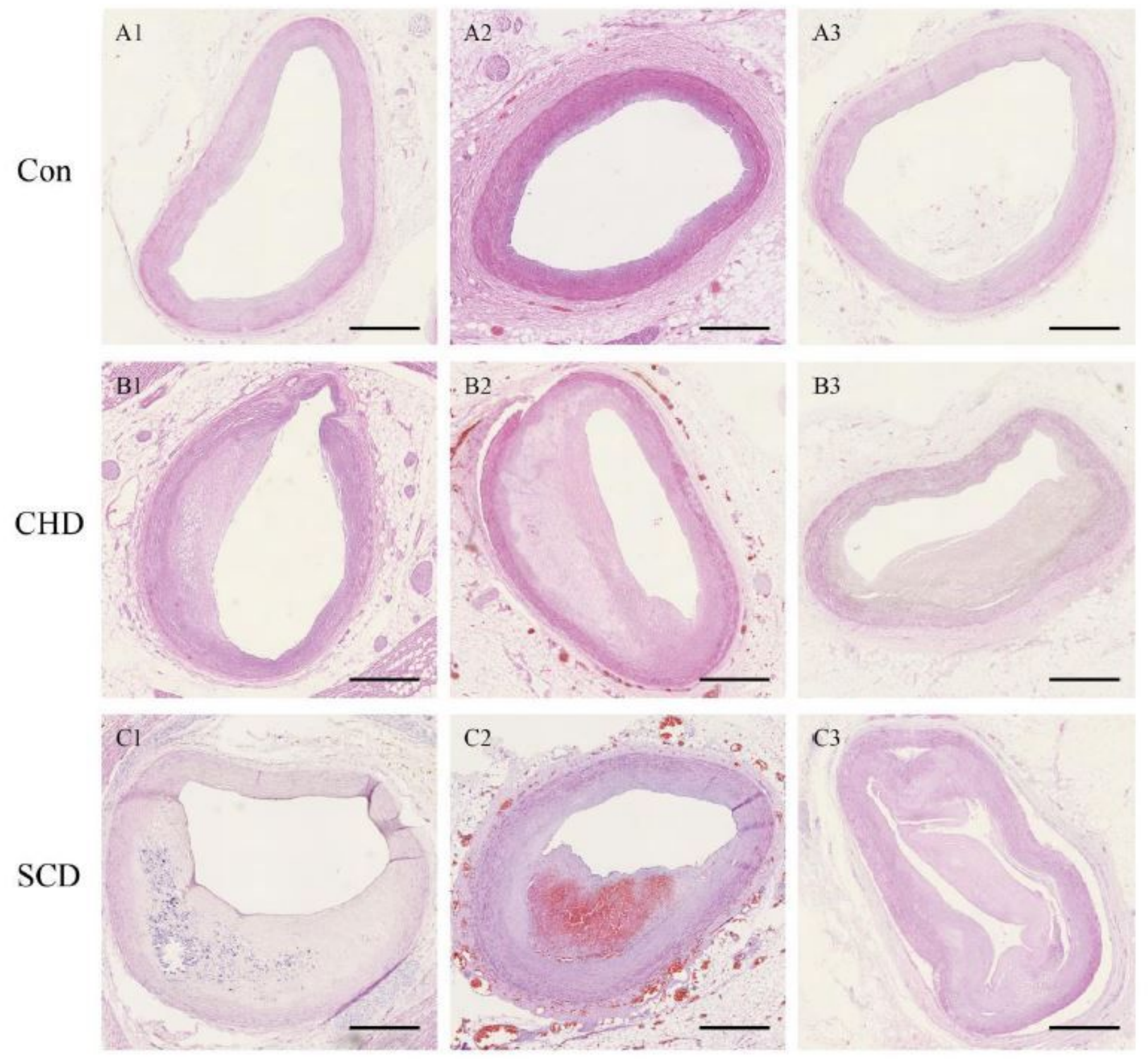

\section{Figure 1}

Microscopic changes in coronary atherosclerosis. A1-A3 Control group, Con. B1-B3 Coronary heart disease group, CHD. C1-C3 Sudden death due to coronary heart disease with intraplaque bleeding and rupture group, SCD. (HE staining, scale bar $=1 \mathrm{~mm}$ ) 


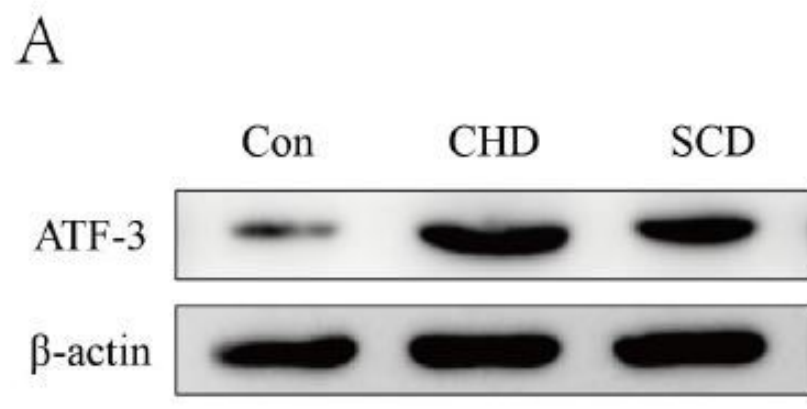

C
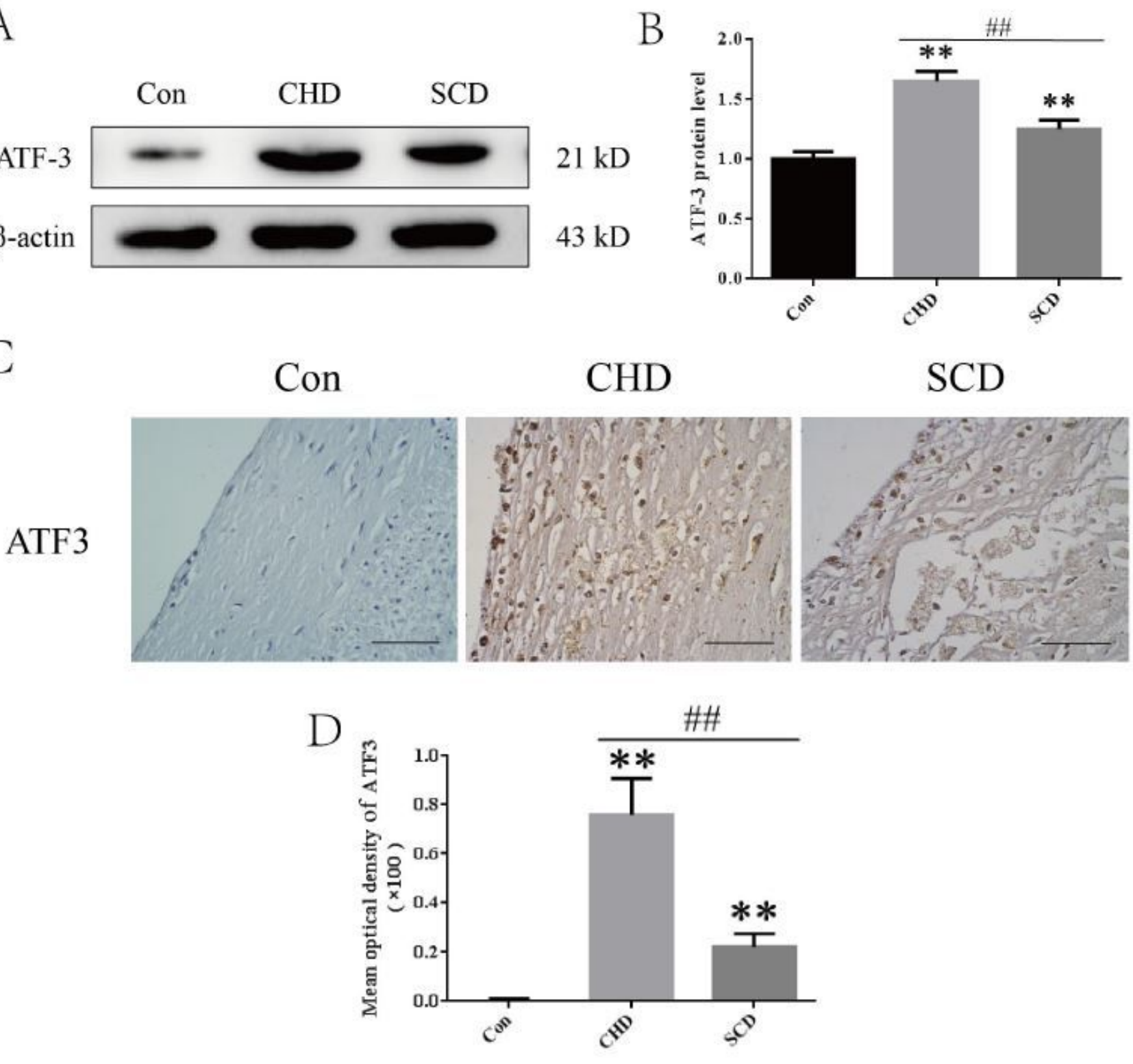

Figure 2

ATF3 expression levels in the coronary artery. A-B Representative Western blot images and quantitative analysis of ATF3 expression levels. C-D Representative immunohistochemical images and quantitative analysis of ATF3 expression in each group (scale bar $=50 \mu \mathrm{m}$ ). All experiments were repeated at least three times. The data are expressed as the mean $\pm S D\left(n=12\right.$ per group). ${ }^{*} P<0.01$ vs the control group; \#\#P $<0.01$ vs the CHD group 


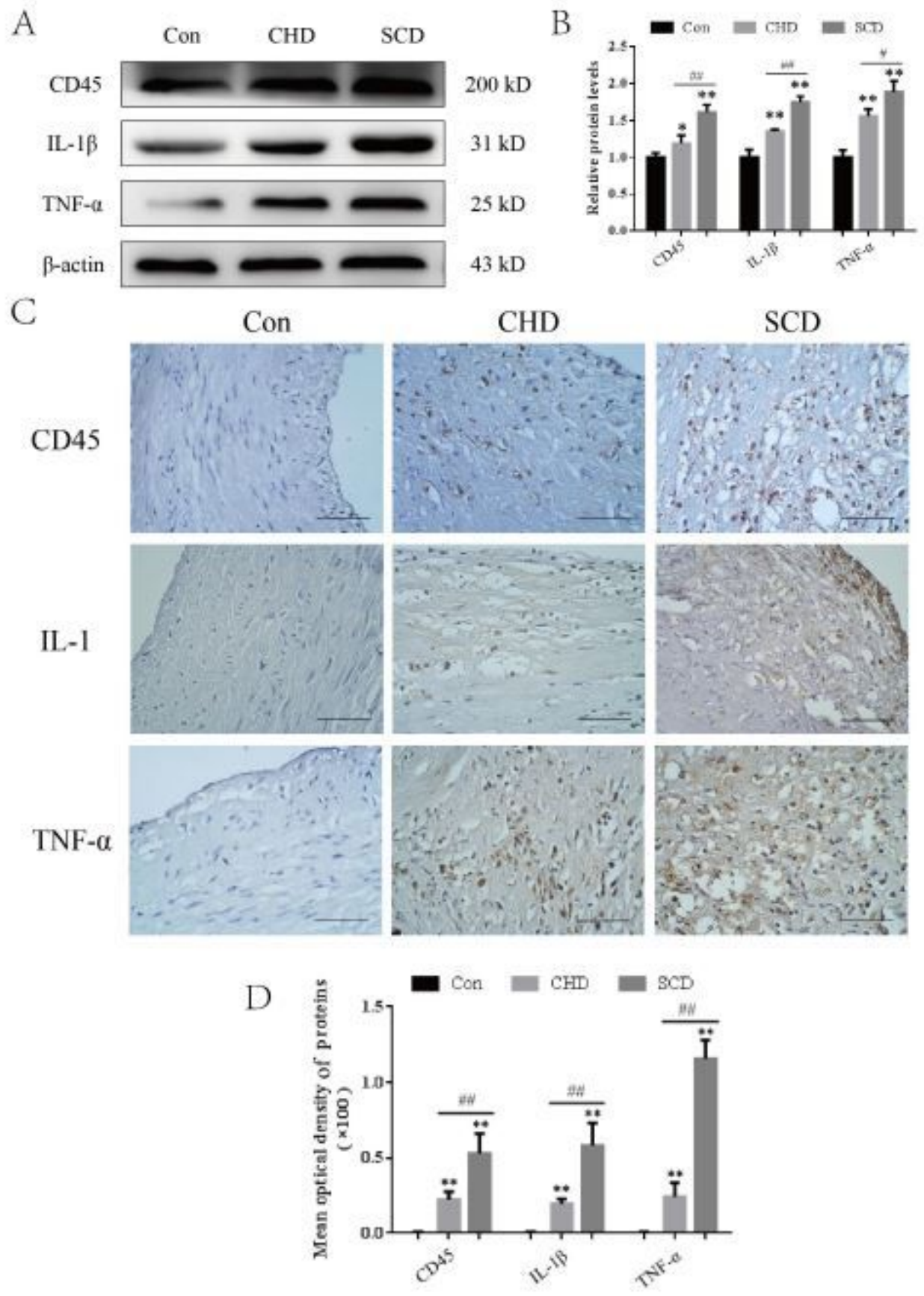

Figure 3

Protein expression levels in the coronary artery. A-B Representative Western blot images and quantitative analysis of protein expression levels. C-D Representative immunohistochemical images and quantitative analysis of protein expression in each group (scale bar $=50 \mu \mathrm{m})$. All experiments were repeated at least three times. The data are expressed as the mean $\pm S D\left(n=12\right.$ per group). ${ }^{*} P<0.05$ vs the control group; $\star \star P<0.01$ vs the control group;\#\#P<0.01 vs the CHD group 

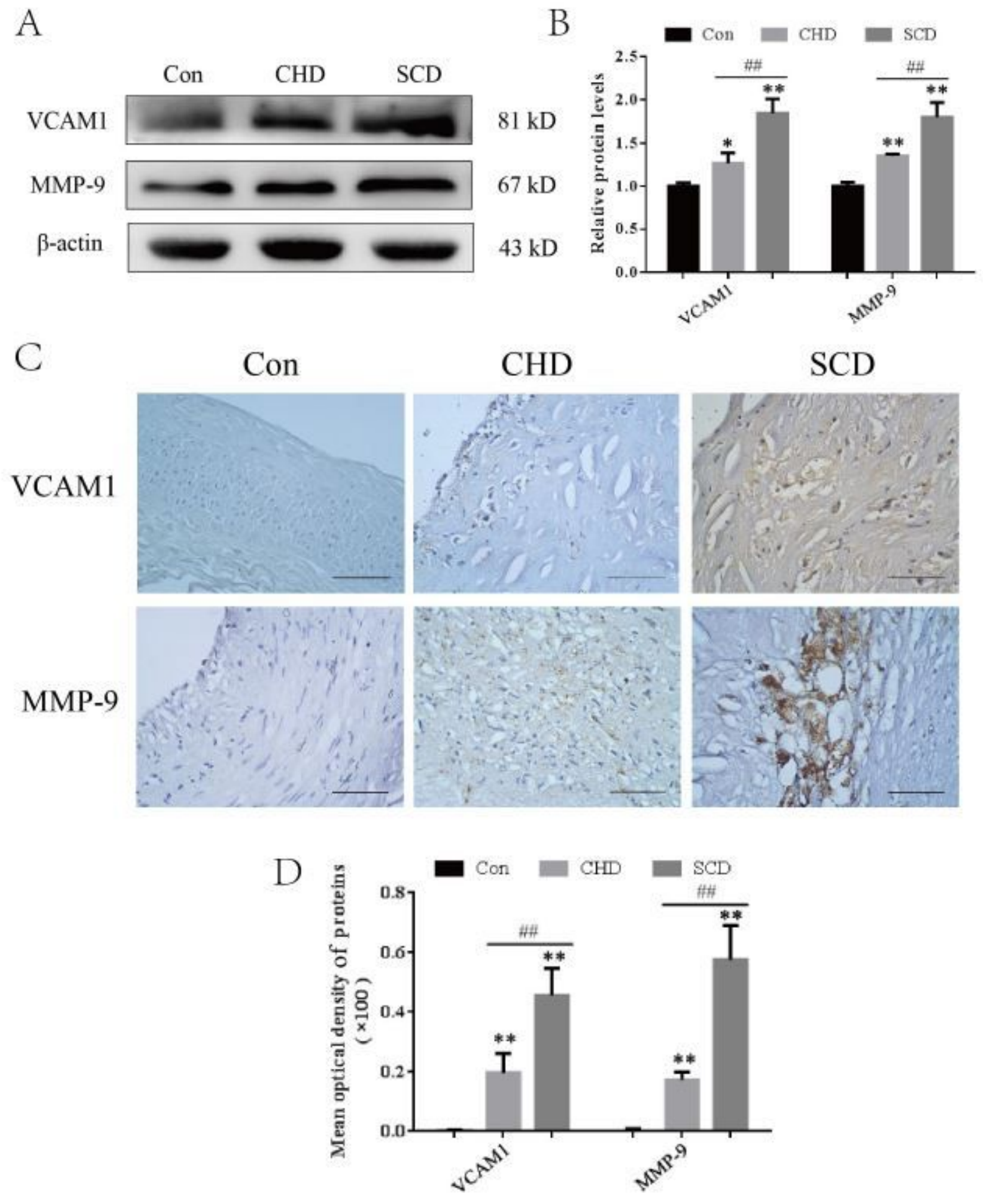

\section{Figure 4}

Protein expression levels in the coronary artery. A-B Representative Western blot images and quantitative analysis of protein expression levels. C-D Representative immunohistochemical images and quantitative analysis of protein expression in each group (scale bar $=50 \mu \mathrm{m})$. All experiments were repeated at least three times. The data are expressed as the mean $\pm S D\left(n=12\right.$ per group). ${ }^{*}<0.05$ vs the control group; $\star \star P<0.01$ vs the control group;\#\#P<0.01 vs the CHD group 
A

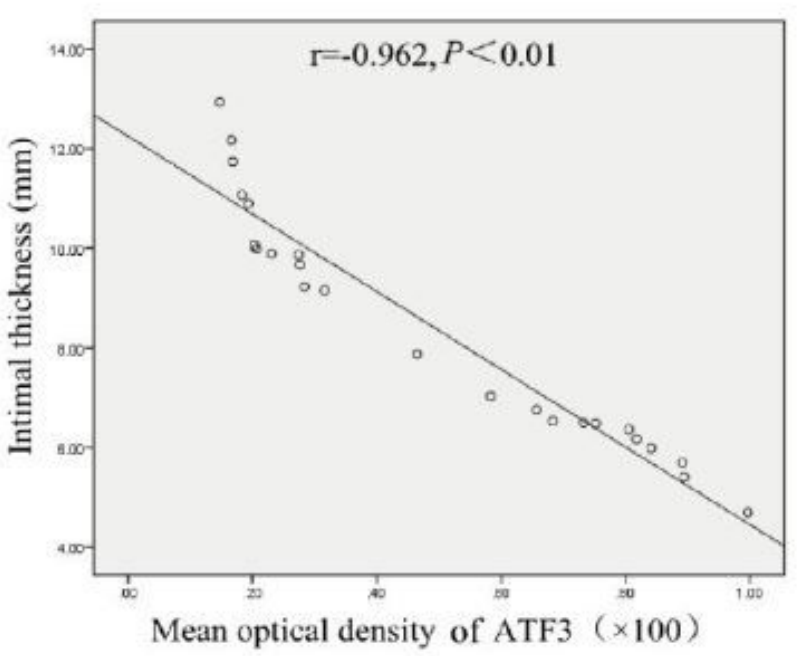

B

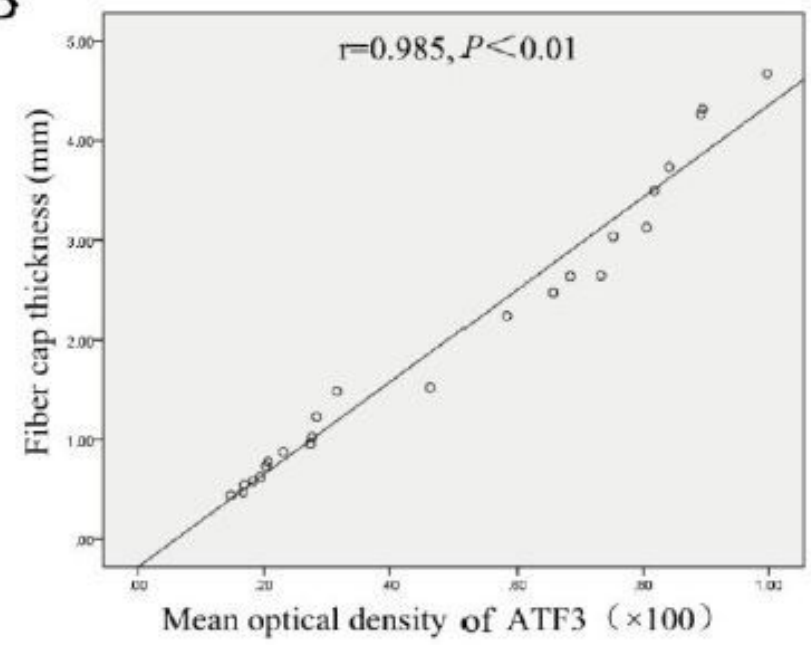

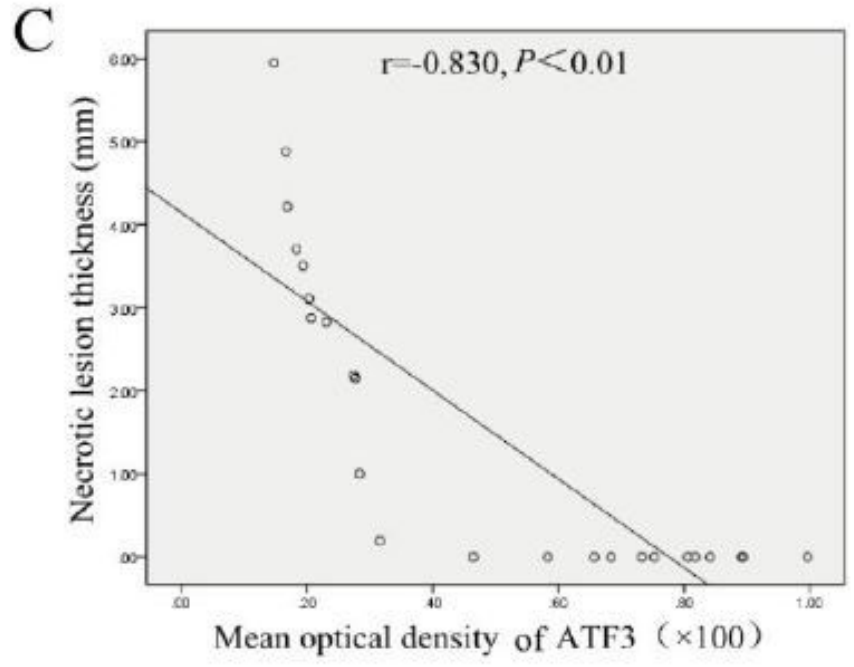

Figure 5

Correlations between the protein level of ATF3 and the structural indexes of the lesion in the lesion group. A-C Intimal thickness, fibrous cap thickness, and necrotic lesion thickness. r: Spearman's correlation coefficient. $P<0.01$ was considered to indicate a significant correlation. 

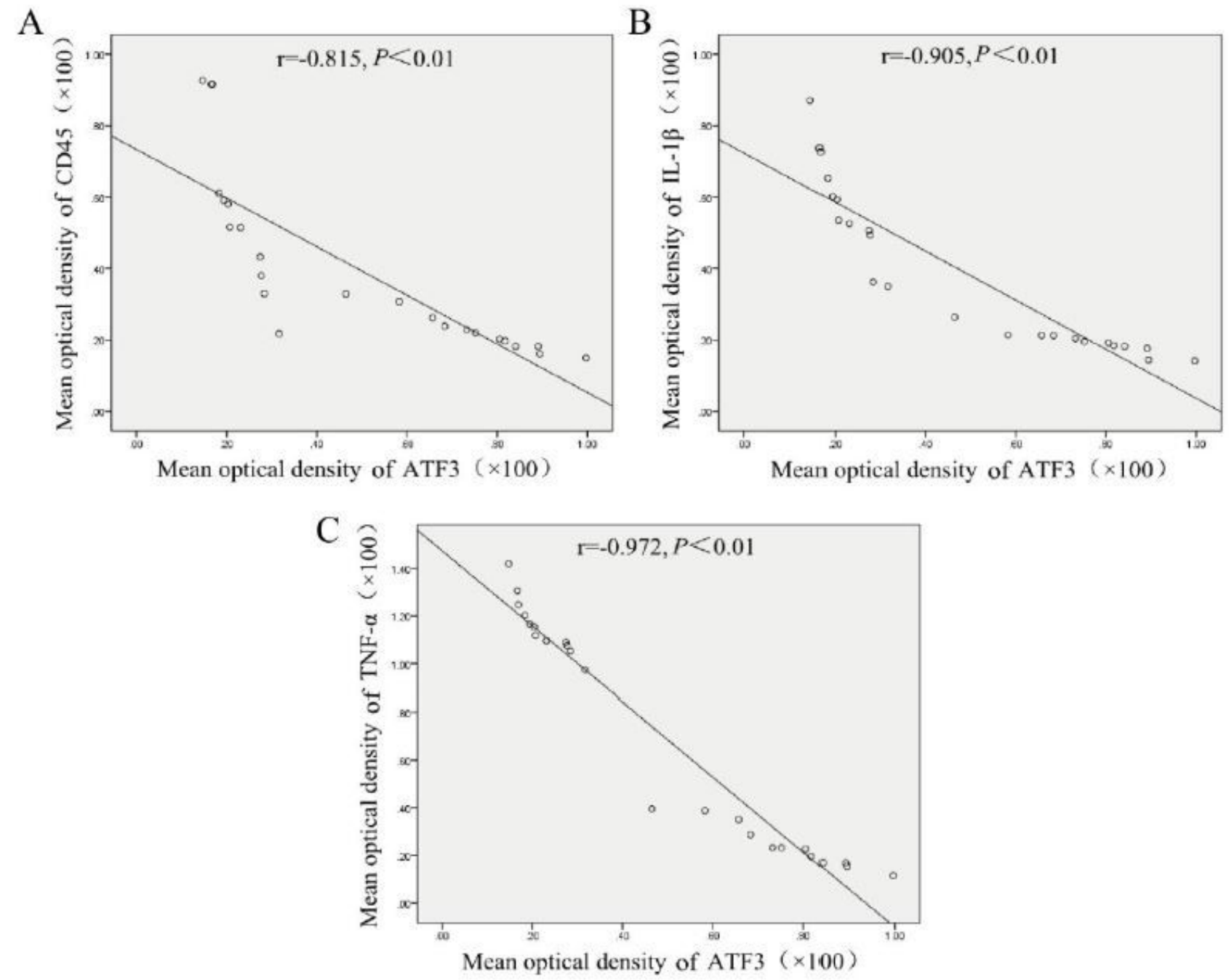

Figure 6

The correlation between ATF3 protein levels and inflammatory factors in the lesion group. r: Spearman's correlation coefficient. A-C CD45, IL-1 $\beta$, and TNF-a. $P<0.01$ was considered to indicate a significant correlation. 
A

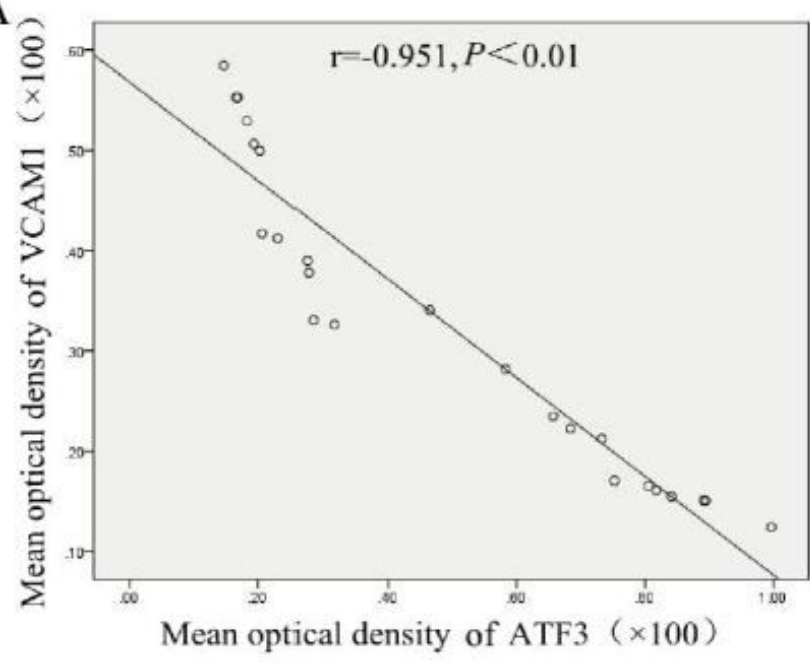

$\mathrm{B}$

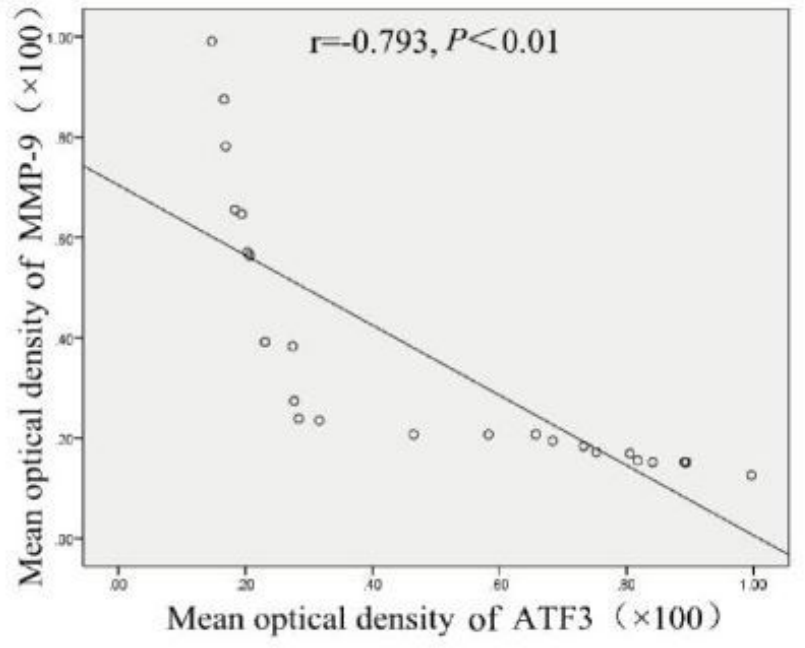

\section{Figure 7}

The correlation between ATF3 protein levels and VCAM1 and MMP-9 in the lesion group. r: Spearman's correlation coefficient. A-B VCAM1, MMP-9. P 0.01 was considered to indicate a significant correlation. 